\title{
Induction of Active Zones at Ectopic Neuromuscular Junctions in the Frog
}

\author{
Chien-Ping Ko and Debra Brown Folsom \\ Section of Neurobiology, Department of Biological Sciences, University of Southern California, Los Angeles, California \\ 90089
}

To examine de novo differentiation of the active zone, ectopic neuromuscular junctions were studied in adult frog muscles. Ectopic junctions induced by excising the original endplate region and implanting the nerve to an endplatefree site were examined by light and electron microscopy 4 weeks-1 year after operations. The earliest time point at which ectopic junction formation was detected with freeze fracture was 6 weeks postoperation, when clusters of active zone particles were observed scattered across the nerve ending. Subsequently, short active zones (6-10 weeks postoperation, length $x=0.36 \pm 0.24 \mu \mathrm{m}$ ) composed of the characteristic 2 double rows of particles are detected. Before junctional folds are observed with freeze fracture, many active zones are parallel to each other and to the long axis of the nerve. The average angle 6-10 weeks postoperation is $27^{\circ} \pm 23^{\circ}$. Even during these early stages of formation, active zones are functional. As time passes, active zones attain a more typical, perpendicular orientation (12-18 weeks postoperation, $z=62^{\circ} \pm 24^{\circ}$ ) and also increase in length ( $x=$ $0.69 \pm 0.45 \mu \mathrm{m})$. However, even after 1 year, the orientation (angle, $\left.x=70^{\circ} \pm 22^{\circ}\right)$ and the length $(x=0.78 \pm 0.63 \mu \mathrm{m})$ of active zones at ectopic junctions are still not well correlated with active zones at normal junctions (normal active zone angle $x=85^{\circ} \pm 5^{\circ}$, length $x=1.00 \pm 0.57 \mu \mathrm{m}$ ). A comparison of the chronologies of ectopic junction formation and junctional fold development supports the hypothesis that the latter may play a role in the induction of active zone differentiation.

A key element in the synapse is the site of transmitter release, the active zone (Couteaux and Pecot-Dechavassine, 1970). Not only does vesicle fusion occur at the active zone (Heuser et al., 1974, 1979), but active zone size is directly correlated with synaptic efficacy (Propst et al., 1986; Propst and Ko, 1987). In the frog neuromuscular junction, the active zone is composed of 2 double rows of large intramembrane particles (Dreyer et al., 1973; Heuser et al., 1974) located precisely opposite a junctional fold and typically perpendicular to the long axis of the nerve ending. Differentiation of this unique membrane specialization has been examined with freeze-fracture electron mi-

\footnotetext{
Received Dec. 12, 1988: revised Mar. 28, 1989; accepted Mar. 29, 1989.

We wish to thank Mary Mosbacher and Mark M. Junge for technical assistance. This work was supported by National Institutes of Health grant NS 17954, Research Career Development Award NS 00728, and a Muscular Dystrophy Association Research Grant

Correspondence should be addressed to Dr. Chien-Ping Ko at the above address. Copyright $($ C) 1989 Society for Neuroscience $0270-6474 / 89 / 103392-08 \$ 02.00 / 0$
}

croscopy previously during regeneration of frog neuromuscular junctions and development of tadpole junctions. After a nerve crush, active zones with normal organization and orientation are restored opposite persistent junctional folds in reinnervated adult frog junctions (Ko, 1984). Even during the initial stages of reinnervation, clusters of active zone particles and short segments of active zones are opposite junctional folds. In contrast, during early stages of development in tadpoles, developing active zones are randomly located and oriented before junctional folds are seen with freeze fracture (Lynch and Ko, 1983; Ko, 1985). Recently, we have shown active zone disorganization following removal of the basal lamina by proteolytic enzyme treatment (Nystrom and Ko, 1988). In addition, it has been shown with thin-section electron microscopy that active zones regenerate and form opposite junctional fold basal lamina even in the absence of muscle fibers (Sanes et al., 1978). These results suggest that active zone differentiation is related to the basal lamina in the junctional fold region.

Since junctional folds are absent in extrasynaptic regions, examining neuromuscular junctions induced at previously endplate-free regions may provide further insights into the differentiation of active zones. Ectopic neuromuscular junctions, complete with nerve terminals and Schwann cells, can be induced de novo in frogs by excising the original endplate sites and implanting the nerve to an endplate-free region of the muscle (Miledi, 1962, 1963; Ding, 1982; Sayers and Tonge, 1984). Accumulation of $\mathrm{ACh}$ receptors and acetylcholinesterase, and the differentiation of new junctional folds (Korneliussen and Sommerschild, 1976; Lomo and Slater, 1980; Breitschmid and Brenner, 1981; Weinberg et al., 1981) are observed in ectopic junctions. Physiological studies have shown by the presence of spontaneous and evoked endplate potentials that ectopic junctions are functional (Miledi, 1962; Sommerschild, 1981; Ding, 1982; Sayers and Tonge, 1984). Ding (1982) has shown that quantal contents at ectopic junctions are approximately 2.5 times larger than normal. However, whether active zones can be formed de novo at extrasynaptic sites has not been reported. One purpose of the present work is to examine the differentiation of active zoncs induced at cctopic ncuromuscular junctions using freezefracture electron microscopy. In addition, active zone lengths are measured to determine whether active zone morphometry may explain the high synaptic efficacy at ectopic junctions observed by Ding (1982).

The present study shows active zones can be induced at ectopic junctions. However, the orientation of active zones during the early stages of ectopic junction formation is nearly parallel to the long axis of the terminal. Over time, the orientation 
gradually shifts toward the normal perpendicular. The sum of active zone lengths per unit length of nerve terminal increases with time but never attains normal size, even after 1 year. A preliminary report has been presented (Ko and Folsom, 1988).

\section{Materials and Methods}

Cutaneous pectoris muscles of the frog, Rana pipiens, were used for this study. Frogs were anesthetized by submersion in $0.1 \%$ Tricaine (Sigma Chemical Co., St. Louis, MO). An incision was made to expose the cutaneous pectoris muscle, and nerves to both sides of the muscle were severed. Ectopic neuromuscular junctions were induced by removing the lower two-thirds of the muscle, including the original neuromuscular region, and implanting the nerve to the remaining muscle portion (Ding, 1982). To facilitate formation of ectopic junctions, the severed nerve was sutured with 7-0 silk to the lateral margin of the operated muscle. After the operation, the skin was sutured closed and the frog allowed to recover in water.

At various times after operations, frogs were killed and the muscles dissected out and bathed in frog Ringer's solution composed of $111 \mathrm{~mm}$ $\mathrm{NaCl}, 2 \mathrm{~mm} \mathrm{KCl}, 1.8 \mathrm{~mm} \mathrm{CaCl}^{2}$, and $5 \mathrm{~mm}$ HEPES, $\mathrm{pH}$ 7.2. Cutaneous pectoris muscles were fixed in 3\% glutaraldehyde in frog Ringer's for 1 $\mathrm{hr}$ then prepared for freeze fracture (Ko, 1981). In some cases, the nerve was stimulated in dilute fixative containing $0.75 \%$ formaldehyde in order to capture synaptic vesicle release (Heuser et al., 1974; Ko, 1984). Muscles were cryoprotected in a series of aqueous glycerol solutions increasing to $30 \%$ glycerol over $1 \mathrm{hr}$. After $2 \mathrm{hr}$ or more in $30 \%$ glycerol, the muscle pieces were sandwiched between gold specimen holders, then rapidly frozen in liquid Freon-22 and stored in liquid nitrogen. Freeze fractures were performed with a complementary replica device (Balzers $400 \mathrm{D})$ at $-110^{\circ} \mathrm{C}$ and $<10^{6}$ Torr. Fractured muscles were shadowed at an angle of $45^{\circ}$ with platinum and carbon and then coated with carbon at $90^{\circ}$. Replicas were stabilized by coating with $0.25 \%$ Lexan (Steere and Erbe, 1983) in ethylene dichloride, cleaned in bleach (Purex, $5.25 \%$ sodium hypochlorite) for $4 \mathrm{hr}$, mounted on grids, then exposed to ethylene dichloride in order to remove the Lexan film. Specimens were examined and photographed on a Jeol 100CXII electron microscope. Active zone length and angle were measured directly from photographic prints placed upon a digitizing tablet (Summagraphics Bitpad) attached to a microcomputer (Northstar Horizon) (Ko, 1984; Propst et al., 1986). For angle measurement, individual micrographs of terminals were oriented such that the longitudinal axis of the nerve terminal was parallel to the natural horizontal axis of the Bitpad. Thus, when individual active zones were traced using the computer mouse, the angle $\left(-90^{\circ}\right.$ to $\left.+90^{\circ}\right)$ of that active zone relative to the longitudinal axis of the nerve terminal was measured. Only the absolute value of the angle was used. No active zone angle measurements were made in cases where the longitudinal axis of the terminal could not be determined or where the active zone consisted of less than 5 pairs of large intramembrane particles.

\section{Results}

To form a basis for comparison with ectopic junctions, a freezefracture view of a nerve ending from a normal cutaneous pectoris muscle is shown in Figure $1 A$. This protoplasmic face shows active zones (arrowhead) opposite the junctional folds (j) which can be identified in freeze-fracture as U- or inverted U-shaped projections of extracellular space between the nerve terminal and the muscle fiber. Most active zones are perpendicular to the long axis of the nerve terminal (n). The average angle between active zones and the terminal axis is $85^{\circ} \pm 5^{\circ}(n$ $=250$ ), and the majority of active zones fall within $80^{\circ}-90^{\circ}$ (also, see Fig. 4D). The average length of an individual active zone in a normal frog is $1.00 \pm 0.57 \mu \mathrm{m}(n=242)$ (also, see Fig. $5 D$ ). Often, more than one active zone segment is aligned with the same junctional fold.

Ectopic junctions were examined by light and electron microscopy at various times after operations. After about 1 month, muscles contract following stimulation. In this early stage of junction formation, nerve endings are typically very short and often consist of small boutons rather than the elongated endings seen in normal junctions (also see Ding, 1982). The earliest successful fracture of an ectopic nerve ending was $41 \mathrm{~d}$ postoperation. At this stage, clusters of large intramembrane particles are scattered across the P-face surface. Most of the particles are not organized, although a few particle aggregates appear as 2 double rows (arrowheads, Fig. $1 B$ ). These primitive active zones are very short and without clear orientation or location compared with active zones at normal neuromuscular junctions (Fig. 1 $A$ ). Junctional folds are not seen in freeze-fracture of these early ectopic junctions.

As time progresses, nerve terminals become elongated and active zone particles are organized into segments of 2 double rows. An example of a freeze-fractured ectopic junction $73 \mathrm{~d}$ postoperation is shown in Figure $1, C$ and $D$. Note that the orientation of these short active zones is approximately parallel to the long axis of the nerve terminal as seen in the low magnification view (arrowheads, Fig. 1C). In a higher-magnification view (Fig. 1D), 2 active zones (arrowheads) lie parallel to each other, as well as to the long axis of the terminal. Dimples, which may represent vesicle openings (arrow, Fig. $1 D$ ), are seen at active zones, suggesting that ectopic active zones are functional despite abnormal orientation. No junctional folds are detected in freeze-fractured ectopic junctions at this stage.

About 4 months postoperation, more active zones appear perpendicular to the longitudinal axis of the nerve terminal. However, there are still some active zones that lie parallel to each other and to the long axis (arrowheads, Fig $2 A$ ). In this endplate, junctional folds still are not apparent. In the junction shown in Figure $2 B$, junctional folds (j) with typical adult morphology arc scen, but not all active zones are located precisely opposite them nor are the active zones necessarily perpendicular to the folds. From Figure $2 B$, it is clear that junctional folds appear before active zones with normal orientation and location are observed. In many instances, even within a single junction, both mature active zones with normal orientation and location (Fig. $2 C$, arrow), as well as active zones with parallel orientation and random location (arrowheads, Fig 2C) are seen. Perhaps the latter are in the process of changing orientation. These results suggest that the orientation and location of active zones are related to the appearance of junctional folds. During the transition period of changing active zone orientation, many active zones (arrowheads, Fig $3 A$ ) with extraordinarily irregular morphology are observed. Some show a $90^{\circ}$ bend, while others are $\mathrm{u}$ - or y-shaped or otherwise abnormally convoluted.

In addition to terminals with elongated morphology, some junctions still show bouton-like nerve endings $12-18$ weeks postoperation. Some bouton-shaped nerve terminals have no discernible longitudinal axis; despite the presence of junctional folds, active zones are randomly located and oriented at various angles (Fig. $3 B$ ). Other boutons have active zones that appear normal, located opposite postjunctional folds as shown in Figure $3 C$. In this figure, active zones (arrowheads), seen here in the exoplasmic face of the nerve bouton, appear as indentations complementary to the protoplasmic face. In addition, particle aggregates (arrows) that represent $\mathrm{ACh}$ receptors (Peng and $\mathrm{Na}-$ kajima, 1978; Yee et al., 1978; Cohen and Pumplin, 1979) are apparent in the protoplasmic face of the muscle fiber.

Seven to 12 months postoperation, more terminals appear normal: active zones are perpendicular to the longitudinal axis and located opposite junctional folds. However, some ectopic junctions still show variations in morphology as described above. 
Namely, boutons are common, as are elongate junctions of shorter-than-normal length.

Changes in the orientation of active zones at ectopic junctions are illustrated quantitatively in Figure 4. From 6 to 10 weeks postoperation (Fig. $4 A$ ), the average angle of ectopic active zones relative to the long axis of the terminal is $27^{\circ} \pm 23^{\circ}(n=53)$. Where primitive active zones lacked distinct organization, the angle of orientation could not be measured for inclusion in the data. Most of the active zones $(65 \%)$ measured from this time period lie within $30^{\circ}$ or less of the horizontal axis. The average angle increases to $62^{\circ} \pm 24^{\circ}(n=646)$ by $12-18$ weeks postoperation (Fig. $4 B$ ). In the histogram, one can see a shift toward larger angles as the junctions become more mature. However, even after 7-12 months (Fig. 4C), a histogram of ectopic active zone orientation is not identical to the normal histogram (Fig. $4 D$ ). The average angle is only $70^{\circ} \pm 22^{\circ}(n=419)$, with $43 \%$ of active zones still less than the mean. In addition, a KolmogorovSmirnov test (Sokal and Rohlf, 1981) shows a significant difference between the distributions of normal and 7-12 month ectopic active zone orientations $(p<0.01)$.

The lengths of individual active zones in ectopic junctions were also measured and are illustrated in Figure 5. In $41 \mathrm{~d}$ ectopic junctions, the length is usually less than $0.3 \mu \mathrm{m}$. Putative active zone particles not in disccrnible rows werc not mcasured. The average length of individual active zones from 6-10 weeks is $0.36 \pm 0.24 \mu \mathrm{m}(n=58)$. At $12-18$ weeks, the average length increases to $0.69 \pm 0.45 \mu \mathrm{m}(n=1044)$. However, even after $7-12$ months, the average length is only $0.78 \pm 0.63 \mu \mathrm{m}(n=$ 622 ), as compared with the normal active zone length of 1.00 $\pm 0.57 \mu \mathrm{m}(n=242)$. The distributions of normal and 7-12 month ectopic active zone lengths are significantly different (Kolmogorov-Smirnov test, $p<0.01$ ).

Probably more significant than the lengths of individual active zones is the total active zone length per unit length of nerve terminal (Propst and Ko, 1987). Such a measurement better identifies differences in active zone distribution along the ectopic nerve terminal compared with normal terminals. From 6 to 10 weeks postoperation, only $24 \mu \mathrm{m}$ of active zone per $100 \mu \mathrm{m}$ of nerve terminal length are observed. At 12-18 weeks, the total active zone length increases to $85 \mu \mathrm{m} / 100 \mu \mathrm{m}$ of terminal; after $7-12$ months, the sum of active zone lengths averages $130 \mu \mathrm{m} /$ $100 \mu \mathrm{m}$ of terminal. In normal adult frog nerve terminals, an average of $156 \mu \mathrm{m}$ of active zones $/ 100 \mu \mathrm{m}$ of terminal has been recorded (Propst et al., 1986). Thus, by this measure also, even long-term ectopic junctions are not equivalent to their normal counterparts.

\section{Discussion}

This study has demonstrated with freeze-fracture for the first time the formation of active zones induced de novo at ectopic neuromuscular junctions. Similar to the initial stages of active zone development in tadpoles and regeneration in normal adults, the primitive form of active zones at ectopic junctions consists of clusters of large intramembrane particles. In reinnervated adult junctions, such clusters of active zone particles are located precisely opposite junctional folds. In contrast, at developing ectopic junctions shown in the present study, as well as in tadpole junctions, even active zones with normal particle organization are located randomly before junctional folds are detected in freeze-fracture. This disparity may be attributed to the presence of persistent junctional folds and/or basal lamina that remain differentiated in adult junctions even after denervation. During development in tadpoles and in initial stages of ectopic junction formation in adults, immaturity of differentiating junctional folds and basal lamina may result in the haphazard distribution of active zones observed. One major difference between normal tadpole and adult ectopic junction formation is the orientation of active zones with respect to the nerve axis once the characteristic particle arrangement is established. In tadpoles, active zones are randomly disposed with respect to the long axis of the nerve ending, and the parallel orientation reported here in ectopic junctions has never been observed. It is not known why ectopic active zones run parallel to each other and to the nerve terminal axis in the early stage of junctional formation or how these active zones gradually shift over time to a more perpendicular orientation. Oddly oriented active zones are not seen exclusively at immature terminals; parallel active zones may be detected even in junctions that already have junctional folds. In fact, active zones with radically different orientations ranging from $0^{\circ}$ to $90^{\circ}$ relative to the long axis of the nerve terminal may be found within the same junction, regardless of the presence of junctional folds. The chronology of ectopic junction formation further suggests that junctional folds and/or basal lamina play important roles in inducing active zone differentiation. Although active zones with normal particle organization can be seen before junctional folds are apparent, the orientation and final location of active zones seems to be related to the presence of junctional folds. Active zones in mammalian neuromuscular junctions are also oriented parallel to the long axis of nerve terminals (Ellisman et al., 1976; Fukunaga et al., 1982). Since mammalian motor nerve endings are in bouton form rather than elongated, parallel active zone orientation may

\begin{abstract}
Figure 1. A, Normal neuromuscular junction. Active zones (arrowhead) along the nerve terminal $(n)$ are aligned with junctional folds $(j)$ in the muscle fiber $(m)$. Active zones have 2 double rows of large, intramembrane particles and usually are oriented perpendicular to the long axis of the nerve terminal. In this and the following freeze-fracture micrographs (except Fig. $3 C$ ), protoplasmic $(P)$ faces of nerve terminals are shown. $B$, Ectopic neuromuscular junctions $41 \mathrm{~d}$ postoperation. Arrowheads indicate intramembrane particles organized into short single or double rows that may represent primitive active zones. $C$ and $D$. Ectopic junction $73 \mathrm{~d}$ postoperation. In the low-magnification view (Fig. $1 C$ ), active zones (arrowheads) parallel to each other and to the long axis of the nerve terminal can be seen. In the high-magnification view (Fig. $1 D$ ), some active zones with the normal double row particle arrangement are seen (arrowhead). Vesicle openings (arrow) are associated with parallel active zones.
\end{abstract}

Figure 2. A, Ectopic junction $118 \mathrm{~d}$ postoperation. Some active zones (arrowheads) are still parallel to each other and to the nerve terminal axis, while others appear more perpendicular. $B$, Ectopic junction $118 \mathrm{~d}$ postoperation. Short segments of active zones (arrowheads) with various orientations are not localized opposite junctional folds $(j)$. C. Ectopic junction $120 \mathrm{~d}$ postoperation. Most active zones (arrows) are perpendicular to the long axis of the nerve ending, but 2 active zones (arrowheads) are still parallel to the axis.

Figure 3. A, Active zones (arrowheads) with irregular morphology seen at ectopic junctions 3-4 months postoperation. $B$, A bouton-like nerve ending at an ectopic junction $120 \mathrm{~d}$ postoperation. Despite the presence of junctional folds $(j)$, active zones (arrowheads) are randomly oriented. $C$, Exoplasmic $(E)$ face of nerve boutons at an ectopic junction $118 \mathrm{~d}$ postoperation. Active zones (arrowheads), which appear as indentations in the membrane, are located opposite junctional folds $(j)$. Clusters of large, intramembrane particles (arrows) that may represent ACh receptors are seen on the muscle membrane. 

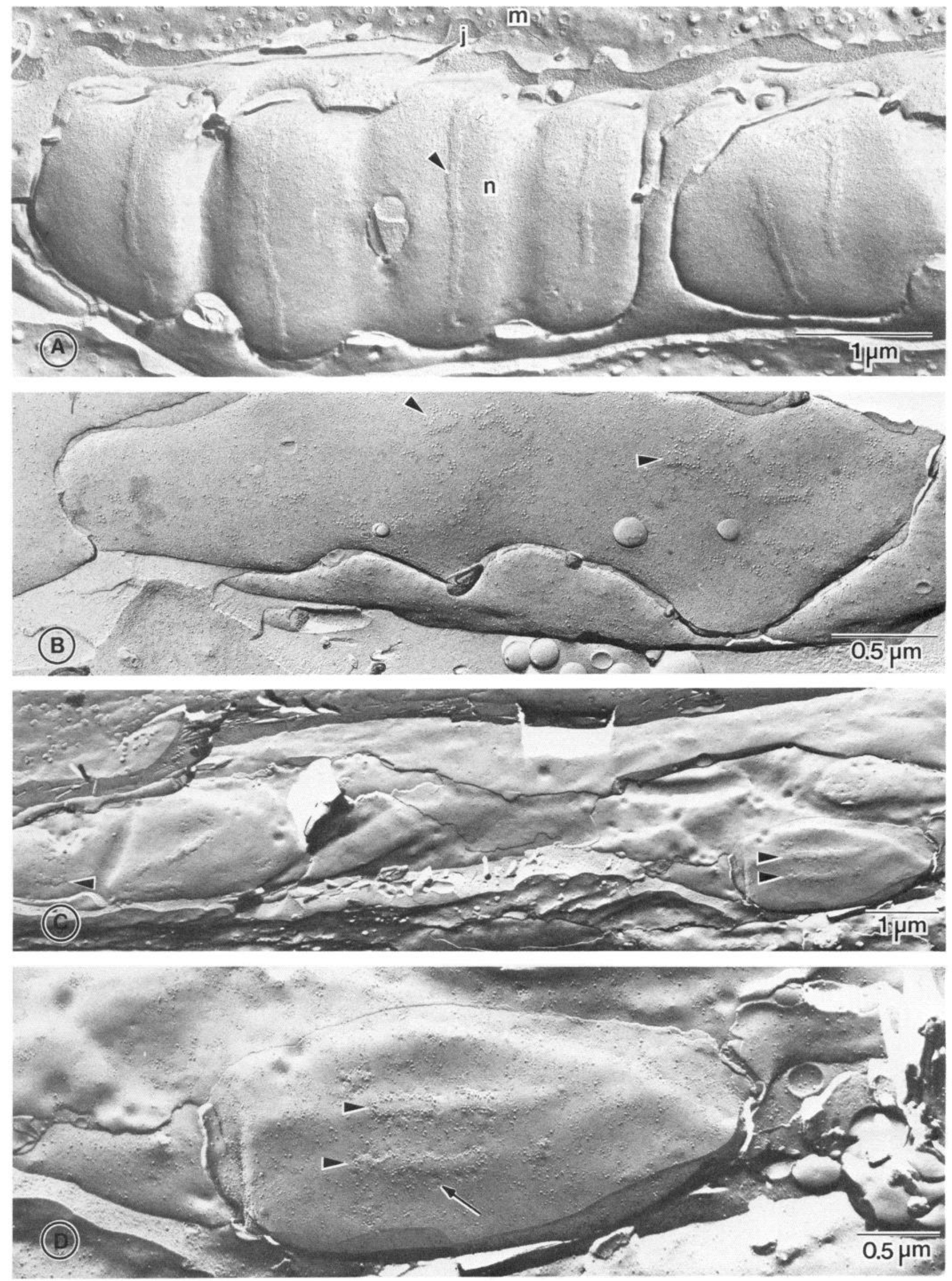

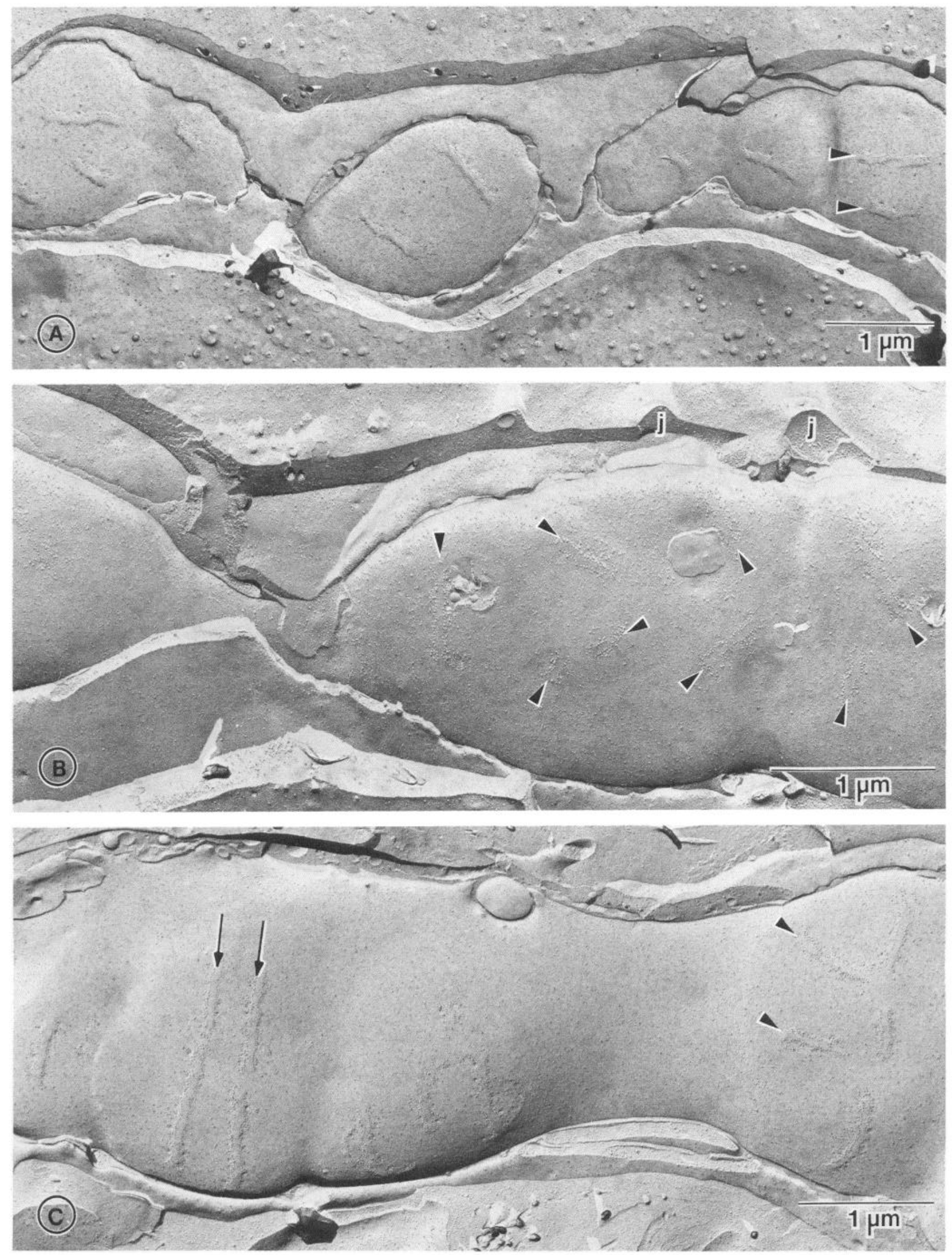

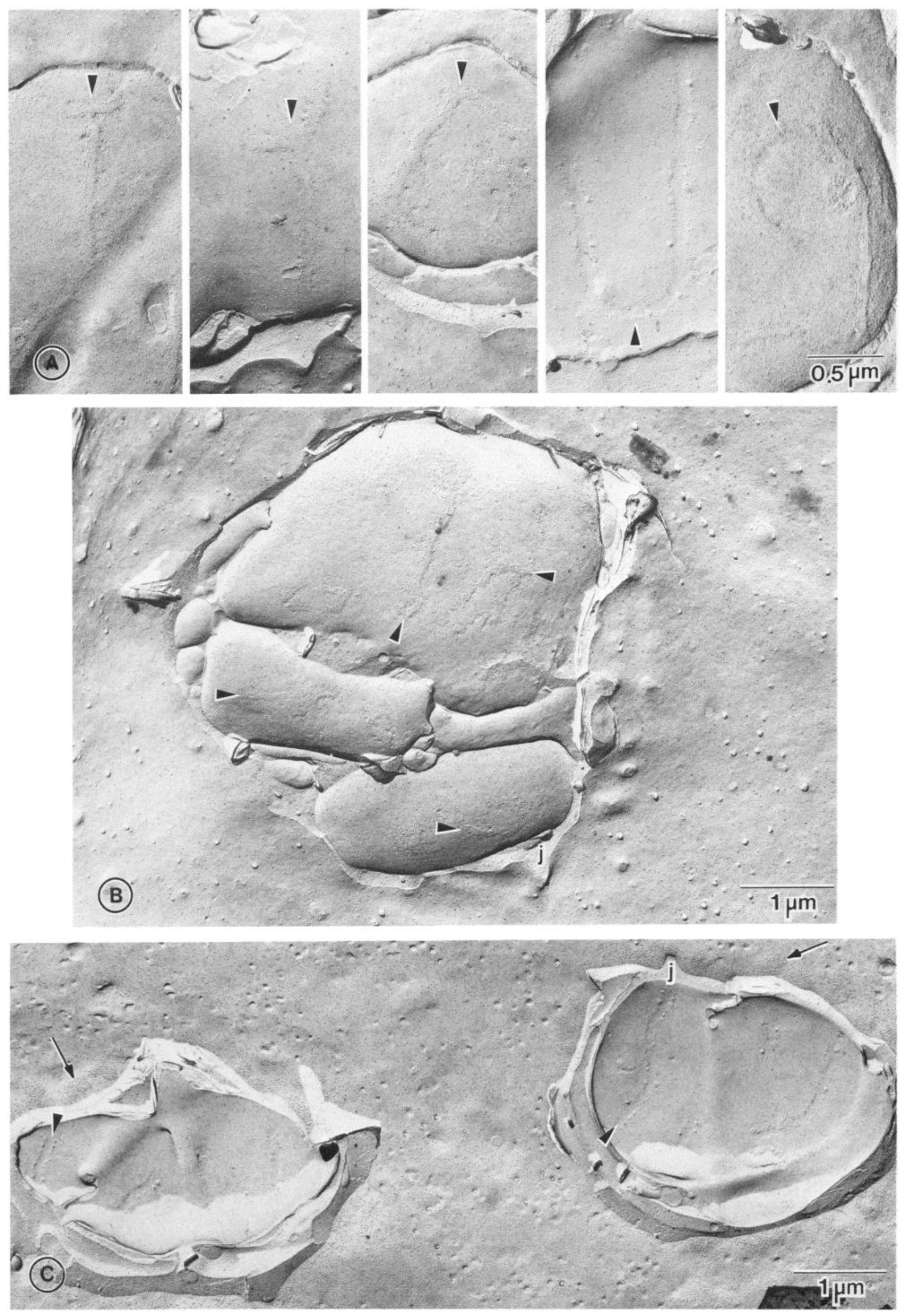
Figure 4. Histograms of angles between active zones and the long axis of nerve terminals in ectopic junctions 6 10 weeks postoperation $(A), 12-18$ weeks postoperation $(B), 7-12$ months postoperation $(C)$, and normal neuromuscular junctions $(D)$. An arrow indicates the mean of each histogram.
Figure 5. Ilistograms of active zone lengths (in $\mu \mathrm{m}$ ) in ectopic junctions 610 weeks postoperation $(A), 12-18$ weeks postoperation $(B), 7-12$ months postoperation $(C)$, and normal neuromuscular junctions $(D)$. An arrow indicates the mean active zone length in each distribution.
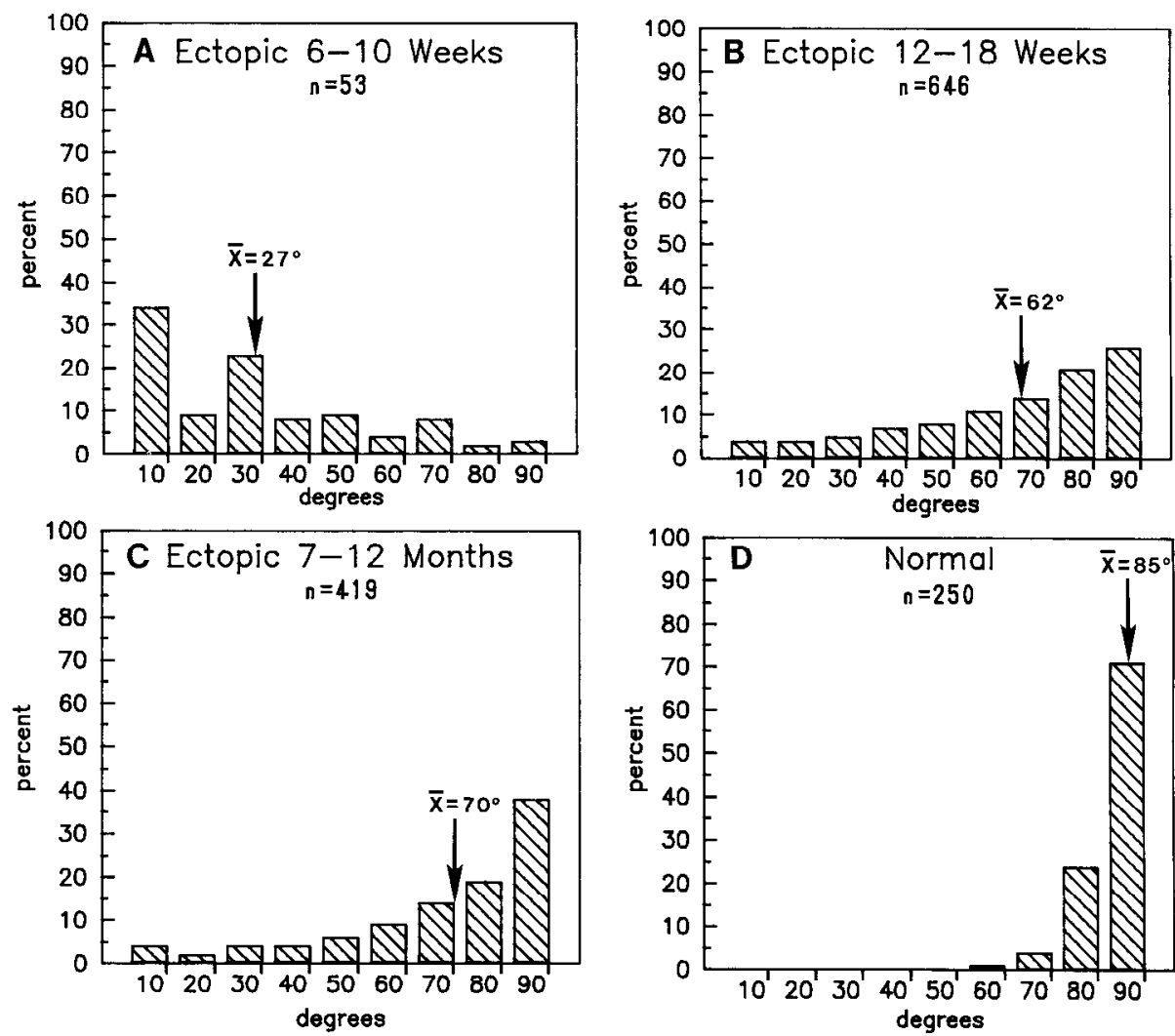
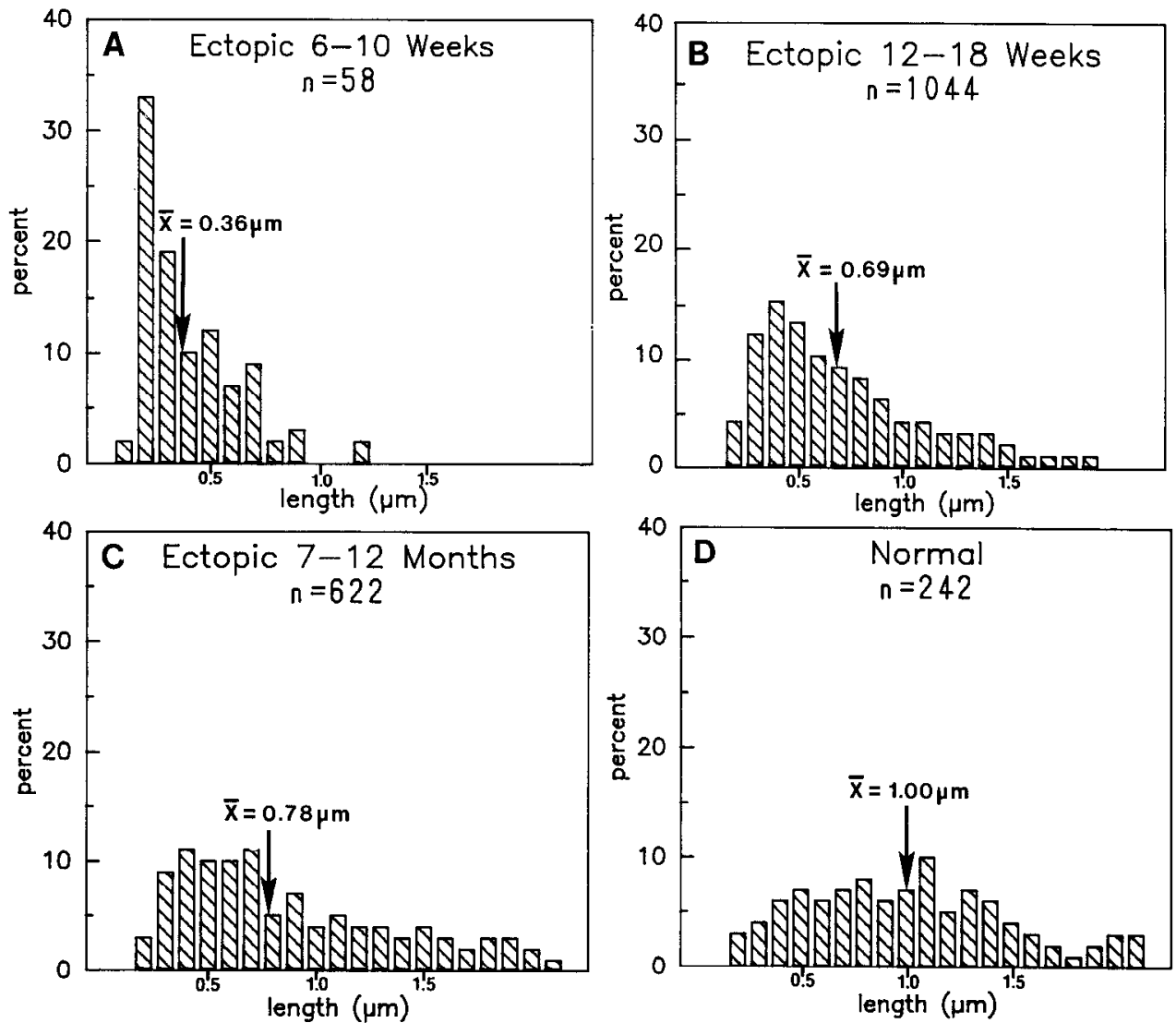
be related to the shape of the nerve terminal. However, normal perpendicular active zone orientation is observed in an ectopic frog junction that already has junctional folds though still in bouton form (Fig. 3C), thus excluding this possibility.

As in both developing and regenerating active zoncs, ectopic active zones are functional during the early stages of formation regardless of orientation. Vesicle openings in close proximity to ectopic active zones further support the hypothesis that active zones are sites of transmitter release. The length of active zones at ectopic junctions increases with time, as is also the case with active zone regeneration in adults and development in tadpoles (Ko, 1984, 1985). Active zone length is correlated with synaptic efficacy (Fukunaga et al., 1982, 1983; Herrera et al., 1985a, b; Walrond and Reese, 1985; Atwood and Lnenicka, 1986; Propst et al., 1986; Propst and Ko, 1987). By freeze-fracturing physiologically identified single muscle fibers, Propst and Ko (1987) have shown that the size of active zone per unit length of junction is correlated with the amount of transmitter release per unit of length of fiber. Thus, it is puzzling that ectopic active zone sizes are not restored to normal even after 1 year, yet ectopic junctions release more transmitter than normal as reported by Ding (1982). However, quantal contents were estimated by the coefficient of variation method, which is probably accurate only to within $25 \%$ as pointed out by Ding (1982). Using this method, Ding reported a mean quantal content of 9.5 from 26 cells studied from 31 to $378 \mathrm{~d}$ ectopic junctions, compared with 3.7 recorded from 18 cells from normal junctions. This 2.6-fold difference could be related in part to the 4-fold increase in input impedances in the muscle stumps at ectopic junctions (Ding, 1982). Thus, the actual physiological difference attributed to active zone sizes between ectopic and normal junctions may be small. To determine whether ectopic active zone morphometry correlated with synaptic efficacy, it would be necessary to combine freeze-fracture and physiological recording in the same neuromuscular junctions.

\section{References}

Atwood, H. L., and G. A. Lnenicka (1986) Structure and function in synapses: Emerging correlations. Trends Neurosci. 9: 248-250.

Breitschmid, P., and H. R. Brenner (1981) Channel gating at frog neuromuscular junctions formed by different cholinergic neurones. $J$. Physiol. (Lond.) 312: 237-252.

Cohen, S. A., and D. W. Pumplin (1979) Clusters of intramembrane particles associated with binding sites for alpha-bungarotoxin in cultured chick myotubes. J. Cell Biol. 82: 494-516.

Couteaux, R., and M. Pecot-Dechavassine (1970) Vesicules synaptiques et pouches au niveau des zones actives de la jonction neuromusculaire. C. R. Hebd. Acad. Sci. Paris D 271: 2346-2349.

Ding, R. (1982) Comparison of morphology and physiology of synapses formed at ectopic and original endplate sites in frog muscle. Brain Res. 253: 57-63.

Dreyer, F., K. Peper, K. Akert, C. Sandri, and H. Moor (1973) Ultrastructurc of the "active zone" in the frog neuromuscular junction. Brain Res. 62: 363-380.

Ellisman, M. H., J. E. Rash, A. Staehelin, and K. R. Porter (1976) Studies of excitable membranes. II. A comparison of specializations at neuromuscular junctions and nonjunctional sarcolemmas of mammalian fast and slow twitch muscle fibers. J. Cell Biol. 68: 752-774.

Fukunaga, H., A. Engel, M. Osame, and H. Lambert (1982) Paucity and disorganization of presynaptic active zones in the Lambert-Eaton myasthenic syndrome. Muscle Nerve 5: 686-697.

Fukunaga, H., A. Engel, B. Lang, J. Newsom-Davis, and A. Vincent (1983) Passive transfer of Lambert-Eaton myasthenic syndrome with IgG from man to mouse depletes the presynaptic active zones. Proc. Natl. Acad. Sci. USA 80: 7636-7640.
Herrera, A. A., A. D. Grinnell, and B. Wolowske (1985a) Ultrastructural correlates of naturally occurring differences in transmitter release efficacy in frog motor nerve terminals. J. Neurocytol. 14: 193-202.

Herrera, A.A., A. D. Grinnell, and B. Wolowske (1985b) Ultrastructural correlates of experimentally altered transmitter release efficacy in frog motor nerve terminals. Neuroscience 16:491-500.

Heuser, J. E., T. S. Reese, and D. M. D. Landis (1974) Functional changes in frog neuromuscular junctions studied with freeze-fracture. J. Neurocytol. 3: 109-131.

Heuser, J. E., T. S. Reese, M. J. Dennis, Y. Jan, L. Jan, and L. Evans (1979) Synaptic vesicle exocytosis captured by quick freezing and correlated with quantal transmitter release. J. Cell Biol. 81: 275-300.

Ko, C.-P. (1981) Electrophysiological and freeze fracture studies of changes following denervation at frog neuromuscular junctions. I. Physiol. (Lond.) 321: 627-639.

Ko, C.-P. (1984) Regeneration of the active zone at the frog neuromuscular junction. J. Cell Biol. 98: 1685-1695.

Ko, C.-P. (1985) Formation of the active zone at developing neuromuscular junctions in larval and adult bullfrogs. J. Neurocytol. 14: 487-512.

Ko, C.-P., and D. B. Folsom (1988) Formation of the active zone at ectopic neuromuscular junctions in the frog. 4th Int. Cong. Cell Biol. Abstr. 274.

Korneliussen, H., and H. Sommerschild (1976) Ultrastructure of the new neuromuscular junctions formed during reinnervation of rat soleus muscle by a foreign nerve. Cell Tissue Res. 167: 439-452.

Lømo, T., and C. Slater (1980) Control of junctional acetylcholinesterase by neural and muscular influences in the rat. J. Physiol. (Lond.) 303: 191-202.

Lynch, K., and C.-P. Ko (1983) Presynaptic active zones at neuromuscular junctions of larval frogs. Dev. Biol. 97: 10-18.

Miledi, R. (1962) Induced innervation of end-plate free muscle segments. Nature 193: 281-282.

Milcdi, R. (1963) Formation of extra nerve-muscle junctions in innervated muscle. Nature 199: 1191-1192.

Nystrom, R., and C.-P. Ko (1988) Disruption of active zones in frog neuromuscular junctions following treatment with proteolytic enzymes. J. Neurocytol. 17: 63-71.

Peng, H. B., and Y. Nakajima (1978) Membrane particle aggregates in innervated and non-innervated cultures of Xenopus embryonic muscle cells. Proc. Nat1. Acad. Sci. USA 75: 500-504.

Propst, J. W., and C.-P. Ko (1987) Correlations between active zone ultrastructure and synaptic function studied with freeze-fracture of physiologically identified neuromuscular junctions. J. Neurosci. 7: 3654-3664.

Propst, J. W., A. A. Herrera, and C.-P. Ko (1986) A comparison of active zone structure in frog neuromuscular junctions from two fast muscles with different synaptic efficacy. J. Ncurocytol. 15: 525-534.

Sanes, J. R., L. M. Marshall, and U. J. McMahan (1978) Reinnervation of muscle fiber basal lamina after removal of myofibers. Differentiation of regenerating axons at original synaptic sites. J. Cell Biol. 78: 176-198.

Sayers, H., and D. A. Tonge (1984) Nerve growth and ectopic synapse formation induced by muscle damage in the frog. J. Physiol. (Lond.) 352: 319-326.

Sokal, R. R., and F. J. Rohlf (1981) Biometry, 2nd ed., W. H. Freeman, San Francisco.

Sommerschild, H. (1981) Formation of ectopic neuromuscular junctions in adult rats. Acta Physiol. Scand. 111:151-158.

Steere, R. L., and E. F. Erbe (1983) Supporting freeze-etch specimens with "lexan" while dissolving biological remains with acids. In Proceedings of the 41 st Annual Meeting of the Electron Microscopy Society of America, G. W. Bailey, ed., pp. 618-619, San Francisco Press, San Francisco.

Walrond, J. P., and T. S. Reese (1985) Structure of axon terminals and active zones at synapses on lizard twitch and tonic muscle fibers. J. Neurosci. 5: 1118-1131.

Weinberg, C. B., J. R. Sanes, and Z. W. Hall (1981) Formation of neuromuscular junctions in adult rats: Accumulation of acetylcholine receptors, acetylcholinesterase and components of synaptic basal lamina. Dev. Biol. 84: 255-266.

Yee, A. G., G. Fischbach, and M. Karnovsky (1978) Clusters of intramembranous particles on cultured myotubes at sites that are highly sensitive to acetylcholine. Proc. Natl. Acad. Sci. USA 78: 6981-6985. 